\title{
FABRICATION AND EVALUATION OF SILICON-CONTAINING APATITE FIBER SCAFFOLDS FOR BONE TISSUE ENGINEERING
}

\author{
Y. Kinoshita ${ }^{1}$, S. M. Best ${ }^{2}$, and M. Aizawa ${ }^{1 *}$ \\ ${ }^{1}$ Department of Applied Chemistry, School of Science and Technology, Meiji University, \\ 1-1-1 Higashimita, Tama-ku, Kawasaki, Kanagawa, Japan 214-8571 \\ ${ }^{2}$ The Cambridge Centre for Medical Materials, Department of Materials Science and Metallurgy, University of \\ Cambridge, Pembroke Street, Cambridge, CB2 3QZ, UK
}

(*Corresponding author: mamorua @isc.meiji.ac.jp)

Keywords: Hydroxyapatite, Apatite fiber, Silicon, Homogeneous precipitation method, Scaffold

\begin{abstract}
The aim of this work is to develop a highly-functional tissue engineering scaffold from silicon-containing apatite fibres (Si-AF). Firstly, Si-AFs were synthesized by a homogeneous precipitation method. Starting solution with a Ca/ $(\mathrm{P}+\mathrm{Si})$ ratio of 1.67 was prepared by mixing $\mathrm{Ca}\left(\mathrm{NO}_{3}\right)_{2} \cdot 4 \mathrm{H}_{2} \mathrm{O},\left(\mathrm{NH}_{4}\right)_{2} \mathrm{HPO}_{4}, \mathrm{Si}\left(\mathrm{OC}_{2} \mathrm{H}_{5}\right)_{4}(\mathrm{TEOS}),\left(\mathrm{NH}_{2}\right)_{2} \mathrm{CO}$ and $\mathrm{HNO}_{3}$. The concentrations of TEOS in the starting solution were $0(\mathrm{AF}), 0.8(0.8 \mathrm{Si}-\mathrm{AF})$ and $1.6(1.6 \mathrm{Si}-\mathrm{AF})$ mass \%. Next, Si-AF scaffolds (Si-AFS) were fabricated by firing the compacts consisting of Si-AF and carbon beads of $150 \mu \mathrm{m}$ diameter. The resulting Si-AFSs were characterized using X-ray diffractometry (XRD), Fourier transform infrared spectroscopy (FT-IR), scanning electron microscopy (SEM) and inductively coupled plasma atomic emission spectrometry (ICP-AES). Results showed that the material properties of the 0.8Si-AFS were similar to those of the conventional AFS without silicon. Consequently, we can conclude that the $0.8 \mathrm{Si}$-AFS offers as a potential novel scaffold material, creating a three-dimensional cell culture environment.
\end{abstract}

(Received March 29, 2012; Accepted April 9, 2012)

\section{INTRODUCTION}

Hydroxyapatite $\left(\mathrm{Ca}_{10}\left(\mathrm{PO}_{4}\right)_{6}(\mathrm{OH})_{2} ; \mathrm{HAp}\right)$ is one of the main inorganic components found in the biological hard tissue, and it has the ability to bond directly with host tissue. Thus, HAp is considered as a material which is suitable for use in the biomedical applications, such as bone grafts and scaffolds for bone tissue engineering [1-3]. Although the composition of HAp is similar to that of the bone mineral, there are a number of distinct differences between the two materials, in terms of their trace ion contents.

In recent investigations, the bioactivity of HAp has shown to increase via substitution of suitable ions into its crystal lattice. It is known that the silicon (Si) is an element which promotes bone formation [4]. Therefore, Si-substituted HAp (Si-HAp) ceramics have a higher bioactivity as compared to pure HAp ceramics [5]. For example, substitution of a minute amount of $\mathrm{Si}$ into the HAp lattice has shown to improve dramatically the rate of bone-bonding ability with the implant materials [6].

The authors have successfully synthesized HAp fibre (AF) by a homogenous precipitation method [7]. Using these AFs, three-dimesional apatite-fiber scaffold (AFS) were fabricated which are suitable for cell culture environment [2]. Furthermore, we have successfully synthesized silicon-containing apatite fibers (Si-AF) by homogeneous precipitation method [8].

Our aim is now to fabricate a highly-functional tissue engineering scaffold from these $\mathrm{Si}-\mathrm{AFs}$, followed by evaluating its material properties.

\section{MATERIALS AND METHODS}

\section{Synthesis of $\mathrm{Si}-\mathrm{AFS}$}

The nominal composition of silicon substitution can be described as $\mathrm{Ca}_{10}\left(\mathrm{PO}_{4}\right)_{6-\mathrm{x}}\left(\mathrm{SiO}_{4}\right)_{\mathrm{x}}(\mathrm{OH})_{2-\mathrm{x}}$. As previously reported in [8], the $\mathrm{Si}-\mathrm{AFs}$ were synthesized by a homogeneous precipitation method. Starting solution with a $\mathrm{Ca} /(\mathrm{P}+\mathrm{Si})$ ratio of 1.67 was prepared by mixing $\mathrm{Ca}\left(\mathrm{NO}_{3}\right)_{2} \cdot 4 \mathrm{H}_{2} \mathrm{O},\left(\mathrm{NH}_{4}\right)_{2} \mathrm{HPO}_{4}$, $\mathrm{Si}\left(\mathrm{OC}_{2} \mathrm{H}_{5}\right)_{4}$ (TEOS), $\left(\mathrm{NH}_{2}\right)_{2} \mathrm{CO}$ and $\mathrm{HNO}_{3}$. The concentrations of TEOS in the starting solution were 0 (AF), 0.8 (0.8Si-AF) and 1.6 mass\% (1.6Si-AF). The precursor phase for the $\mathrm{Si}-\mathrm{AF}$, octacalcium phosphate $\left(\mathrm{Ca}_{8} \mathrm{H}_{2}\left(\mathrm{PO}_{4}\right)_{6} \cdot 5 \mathrm{H}_{2} \mathrm{O} ; \mathrm{OCP}\right)$ fibers, were firstly prepared by heating the starting solution at $80{ }^{\circ} \mathrm{C}$ for $24 \mathrm{~h}$. The resulting OCP fibers were then transformed into Si-AF by heating at $95^{\circ} \mathrm{C}$ for $144 \mathrm{~h}$ in the presence of TEOS. On the other hand, AF ( $\mathrm{Si}$ content 0 mass \%) was prepared by heating at $80{ }^{\circ} \mathrm{C}$ for $24 \mathrm{~h}$, followed by heating at $90{ }^{\circ} \mathrm{C}$ for $72 \mathrm{~h}$ [8]. 


\section{Fabrication of Si-AFS}

Spherical carbon beads with a diameter of $\sim 150$ $\mu \mathrm{m}$ were added to the Si-AF slurry (1 mass \% Si-AF in the mixed solvent of ethanol/water $=1 / 1(\mathrm{v} / \mathrm{v}))$ with a carbon/Si-AF (w/w) ratio of $0,10 / 1$ and 20/1. The compacts for scaffolds were then fabricated by pouring and vacuum pumping the carbon beads-containing Si-AF slurry into the vinyl-chloride mold. The resulting compacts were fired at $1300{ }^{\circ} \mathrm{C}$ for $5 \mathrm{~h}$ in a humidified atmosphere to fabricate the Si-AFS. Here, scaffolds with a carbon/Si-AF (w/w) ratio of $0,10 / 1$ and 20/1 are referred to as Si-AFS0, Si-AFS1000 and Si-AFS2000.

The Si-AFs and Si-AFSs were characterized by X-ray diffractometry (XRD), Fourier-transform infrared spectroscopy (FT-IR), scanning electron microscopy (SEM) and inductively coupled plasma atomic emission spectrometry (ICP-AES).

\section{RESULTS AND DISCUSSION}

\section{Characterization of $\mathrm{Si}-\mathrm{AFs}$}

Figure 1 shows the typical XRD patterns of the Si-AFs. XRD patterns of the AF, 0.8Si-AF and 1.6Si-AF indicated the single-phase HAp. Figure 2 shows the typical FT-IR spectra of the Si-AFs. In the FT-IR spectra of the above Si-AFs, the absorptions assigned to the $\mathrm{PO}_{4}{ }^{3-}$ groups at 1300-900, 600 and $570 \mathrm{~cm}^{-1}$ and assigned to the $\mathrm{OH}^{-}$group at $3570 \mathrm{~cm}^{-1}$, were detected. In addition, the absorptions assigned to $\mathrm{CO}_{3}{ }^{2-}$ groups were detected at 1460,1420 and 880 $\mathrm{cm}^{-1}$. These absorptions indicate that the present $\mathrm{Si}$-AFs were consisted of carbonate-containing apatite. The Si content of the Si-AFs increased in proportion to the amount of Si added as given Table 1 . Figure 3(a) shows the typical SEM micrograph of the $\mathrm{Si}-\mathrm{AF}$. The SEM micrographs indicate that the Si-AFs were approximately $60-100 \mu \mathrm{m}$ in length.

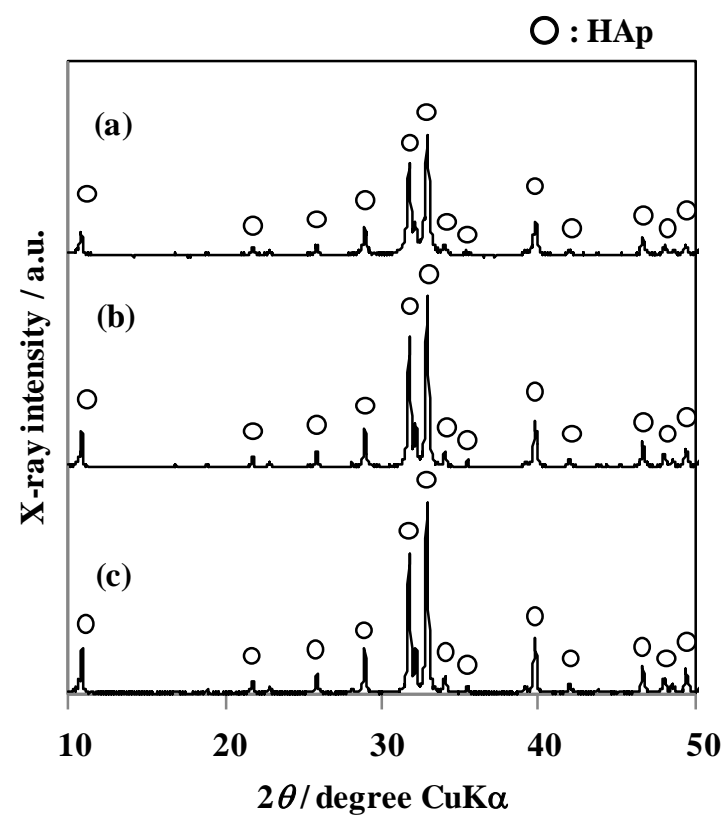

Fig. 1 XRD pattern of the Si-AFs: (a) 1.6Si-AF, (b) 0.8Si-AF, (c) $\mathrm{AF}$

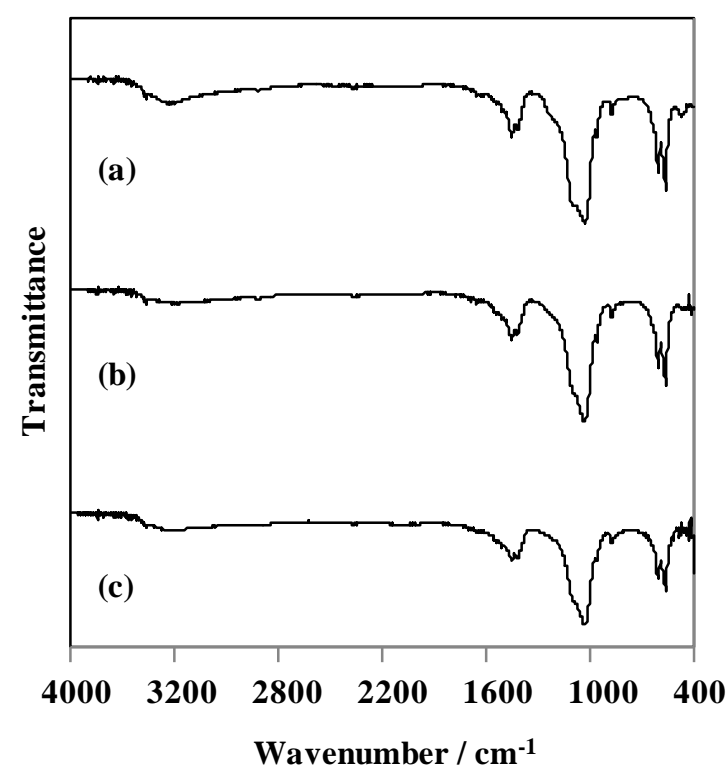

Fig. 2 FT-IR spectra of the Si-AFs: (a) 1.6Si-AF, (b) 0.8Si-AF, (c) AF

Table 1 Chemical compositions of Si-AFs and Si-AFSs

\begin{tabular}{|c|c|c|c|c|c|c|}
\hline \multicolumn{2}{|c|}{ Sample } & \multirow{2}{*}{$\frac{\mathrm{Ca} / \mathrm{mass} \%}{\mathbf{3 9 . 9 0}}$} & \multirow{2}{*}{$\frac{\mathrm{P} / \mathrm{mass} \%}{\mathbf{1 8 . 5 1}}$} & \multirow{2}{*}{$\frac{\mathrm{Si} / \operatorname{mass} \%}{-}$} & \multirow{2}{*}{$\frac{\mathrm{Ca} / \mathrm{P}}{1.67}$} & \multirow{2}{*}{$\frac{\mathrm{Ca} /(\mathrm{P}+\mathrm{Si})}{1.67}$} \\
\hline & $\mathrm{AF}$ & & & & & \\
\hline $\begin{array}{c}\text { nominal } \\
\text { composition }\end{array}$ & $0.8 \mathrm{Si}-\mathrm{AF}$ & 40.12 & 17.74 & 0.80 & 1.75 & 1.67 \\
\hline & 1.6Si-AF & 40.35 & 16.96 & 1.60 & 1.84 & 1.67 \\
\hline \multirow{3}{*}{ as-prepared } & $\mathrm{AF}$ & 37.21 & 16.88 & - & 1.70 & 1.70 \\
\hline & $0.8 \mathrm{Si}-\mathrm{AF}$ & 40.28 & 18.29 & 0.66 & 1.70 & 1.64 \\
\hline & 1.6Si-AF & 35.56 & 16.23 & 1.18 & 1.69 & 1.57 \\
\hline \multirow{3}{*}{ fired } & AFS & 39.68 & 18.32 & - & 1.67 & 1.67 \\
\hline & 0.8Si-AFS & 37.88 & 17.59 & 1.00 & 1.66 & 1.57 \\
\hline & 1.6Si-AFS & 38.61 & 17.70 & 1.66 & 1.69 & 1.53 \\
\hline
\end{tabular}



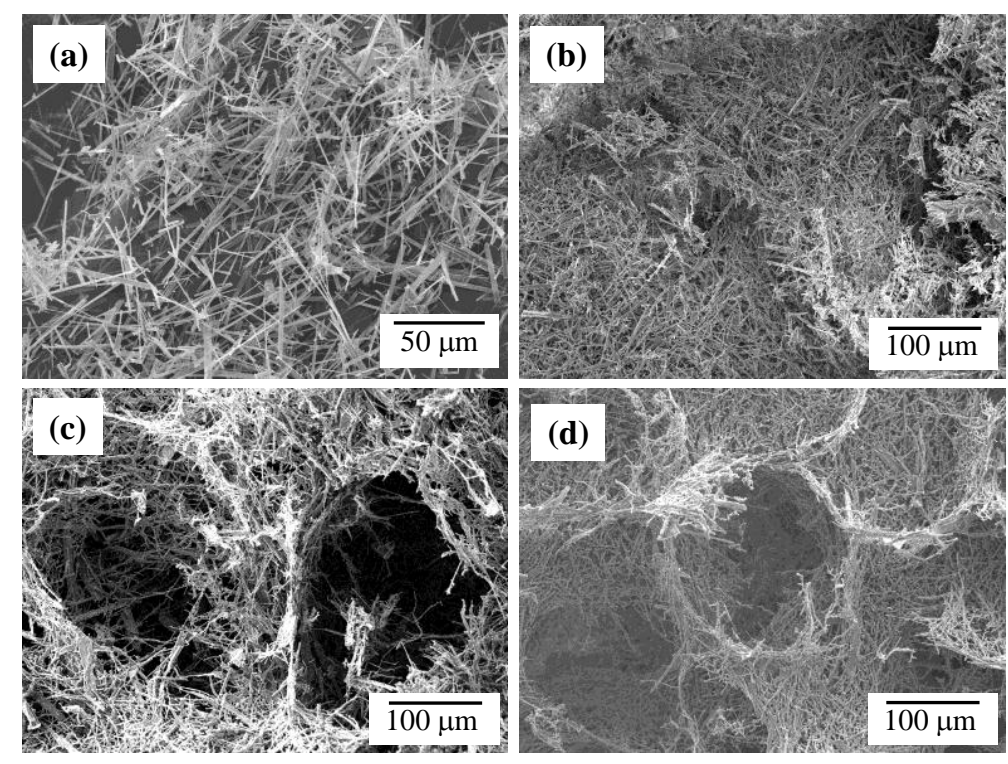

Fig. 3 SEM micrographs of the Si-AF and the Si-AFSs:

(a) 0.8Si-AF, (b) 0.8Si-AFS0,

(c) 0.8Si-AFS1000, (d) 0.8Si-AFS2000.

\section{Characterization of Si-AFSs}

Figure 4 shows the typical XRD patterns of the Si-AFSs. The XRD pattern indicated that the AFS was single-phase HAp. However, a small amount of $\alpha$-tricalcium phosphate ( $\alpha$-TCP) was detected for the $0.8 \mathrm{Si}-\mathrm{AFS}$. As for the 1.6Si-AFS, they were thermally decomposed into $\alpha$-TCP and $\beta$-TCP phases. Generally, Si-AFSs decomposed with increasing silicon addition.

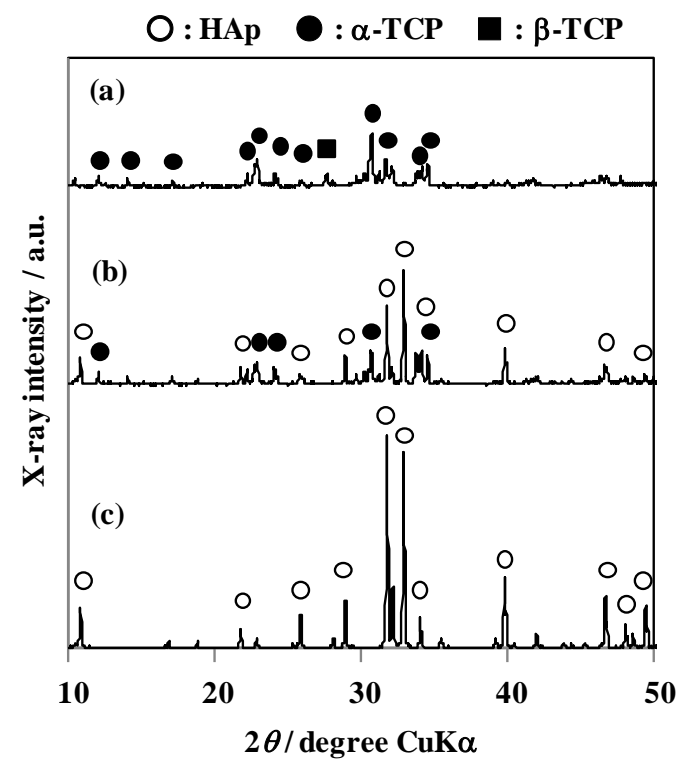

Fig. 4 XRD pattern of the Si-AFSs:

(a) 1.6Si-AFS1000, (b) 0.8Si-AFS1000, (c) AFS1000
Figure 5 shows the typical FT-IR spectra of the Si-AFSs. In the FT-IR spectra, the absorptions assigned to the $\mathrm{PO}_{4}{ }^{3-}$ groups were detected at 1300-900, 600 and $570 \mathrm{~cm}^{-1}$, together with those assigned to the $\mathrm{OH}^{-}$groups at $3570 \mathrm{~cm}^{-1}$. The $\mathrm{CO}_{3}{ }^{2-}$ groups were not detected after firing.

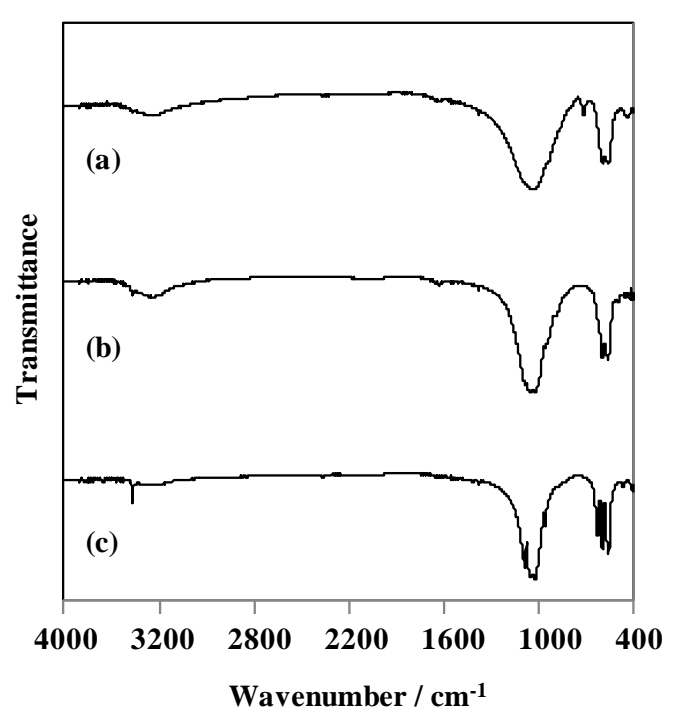

Fig. 5 FT-IR spectra of the Si-AFSs:

(a) 1.6Si-AFS1000, (b) 0.8Si-AFS1000, (c) AFS1000 
Figures 3(b)-(d) show typical SEM micrographs of the Si-AFSs. The microstructures of 0.8Si-AFS1000 (Fig. 3(c)) and 0.8Si-AFS2000 (Fig. 3(d)) contained lots of macropores of sizes ranging from 100 to $150 \mu \mathrm{m}$. The porosity level of 0.8Si-AFS0, 0.8Si-AFS1000 and 0.8Si-AFS 2000 were $90.3 \%, 97.8 \%$ and $98.4 \%$, respectively. It was noted from this work that the porosity level of Si-AFSs increased with the numbers of carbon beads used.

The $\mathrm{Ca}, \mathrm{P}$ and $\mathrm{Si}$ contents of the samples were determined using ICP-AES. Table 1 shows the chemical compositions of Si-AFSs. It revealed that $\mathrm{Si}$ was present in the $\mathrm{Si}$-AFSs after firing. In addition, Si composition of Si-AFS was similar to the nominal composition.

The effect of $\mathrm{Si}$ substitution on the crystal structure of HAp was examined by determining the lattice constants. The 1.6Si-AFS was not measured due to the presence of TCP phase in the material.

The $0.8 \mathrm{Si}$-AFS resulted in a decrease in the $a$-axis and an increase in the $c$-axis of the unit cell of HAp. This variation of lattice constant was in good agreement with the Si-substituted HAp studies reported by Gibson et al. [5].

It can be deduced that $\mathrm{Si}$ is incorporated in the HAp crystal structure from the lattice constant variation of $0.8 \mathrm{Si}-\mathrm{AFS}$.

\section{CONCLUSIONS}

The Si-AFs were synthesied successfully by a homogenous precipitation method. XRD analysis revealed that these fibres were mainly crystalline HAp phase. Furthermore, the material properties of the $0.8 \mathrm{Si}$-AFS were similar to those of AFS. On the whole, the 0.8Si-AFS offers as a potential novel scaffold material, creating a three-dimensional cell culture environment.

\section{REFERENCES}

[1] L. L. Hench, J. Am Ceram. Soc., 81, 1705-28 (1998)

[2] M. Aizawa, H. Shinoda, H. Uchida, I. Okada, T. J. Fujimi, N. Kanzawa, H. Morisue, M. Matsumoto

and Y. Toyama Phosphorus Res. Bull., 17, pp. 262-268 (2004).

[3] M. Honda, T. Fujimi, S. Izumi, K. Izawa, M. Aizawa, H. Morisue, T. Tsuchiya, N. Kanzawa $J$. Biomed. Mater. Res.: Part A, 94A, pp. 937-944(2010).

[4] E. M. Carlisle, Science, 167, pp. 279-280 (1970).

[5] I. R. Gibson, S. M. Best and W. Bonfield, J. Biomed.Mater. Res., 44, pp.422-428 (1999).

[6] A. E. Porter, S. M. Best and W. Bonfield, J. Biomed. Mater. Res., 68A, pp.133-141 (2003)

[7] M. Aizawa, N. Patel, A. E. Poter, S. M. Best and W. Bonfield, Key Eng. Mater. 309-311, pp1129-1132 (2006).

[8] M. Aizawa, A. E. Porter, S. M. Best and W. Bonfield, Biomaterials, 26, pp. 3427-3433 (2005). 